\author{
SEUNGSIN LEE Konkuk University \\ DEOKSOON YANG* Korean Institute for Consumer Education \\ JONGHYE LEE** Korean Institute for Consumer Education \\ YOUNGHEE LEE*** University of Houston \\ SUNKYUNG HEO**** Korea Food \& Drug Administration
}

\title{
A Study on the Discrimination and the Real State of High Calorie Foods with Low Nutrition Values in Children's Snacks sold within Green Food Zone
}

This study surveys the state of 'children's snacks' sold within the Green Food Zone and that of High Calorie Foods with Low Nutrition Value (HCFLNV). The main purposes are the analyses of foods in accordance to KFDA Program for HCFLNV and an analysis of differences in HCFLNV that are dependent on relevant factors such as food types, school types, origins, the scale of manufacturing company, area and price. Based on the analyses, educational and political implications have been sought that will form nutritious dietary habits, contribute to the prevention of obesity, and improve health in child consumers. The methodologies of

$\dagger$ This research was supported by a grant (08082KFDA999) from Korea Food \& Drug Administration in 2010 for Safety Assurance on Food and Eating/Nutrition EnvironmenT (SAFENET) for Children.

Professor, Dept. of Consumer Information Science, Konkuk University, Seoul, Korea (Lchung@konkuk.ac.kr)

${ }^{*}$ Senior Researcher, Korean Institute for Consumer Education, Seoul, Korea(Corresponding Author)

${ }^{*}$ Secretary-General, Korean Institute for Consumer Education, Seoul, Korea

${ }^{* * *}$ Visiting scholar, University of Houston, Texas, USA

${ }^{* * * \star}$ Assistant Director, Children's Dietary Life Safety Division, Korea Food \& Drug Administration

Key Words: Consumer Safety, Children Consumer, HCFLNV (High Calorie Foods with Low Nutrition Value), Children's Snacks, Food Safety this study are literature studies and surveys. The results of this study can be summarized as following. First, the number of children's snacks is 517 items of total 645 gathered within 150 Green Food Zones. Candies are the most popular item, next are cookies, chocolates, and breads. Second, in the real state survey there are 186 HCFLNV (36.0\%) among children's snacks sold within Green Food Zone. Based on the survey results, the marking of HCFLNV on the package of children's snacks and the extension of the ban of HCFLNV sales to all stores within the Green Food Zone are strongly suggested. This provides preliminary data related to children's snacks and food safety. With enforcement of the Special Act on the Safety Management of Children's Dietary Life, the rate of HCFLNV has decreased and the child snack product environment in stores has improved. However, it is necessary to supervise low-priced snacks and promote an awareness of HCFLNV along with the child consumer education of food safety is needed.

More consumers are concerned about food safety due to the increase in income and improved consumer consciousness. The results of the Social Survey in Korea are that $37.3 \%$ of people over 15 years of age are concerned about food safety; in addition, $52.1 \%$ of them have worries about the foods sold within the stores of Green Food Zone (Korea Statistics Office, 2010). Recently the child obesity rate continues to increase and is now $13.2 \%$ 
(Ministry of Education, Science and Technology: MEST, 2010). A leading cause of obesity is high calorie foods with low nutrition value (HCFLNV) such as candy, pizza, vegetable beverage, chocolates, potato chips, and sodas are a significant cause. A total of $49.6 \%$ of primary school students, $56.7 \%$ of middle school students, and $60.2 \%$ of high school students indicated that they have fast foods (such as hamburgers) more than once a week and instant noodles more than twice a week (MEST, Ministry of Health and Welfare: MHW \& Korea Centers of Disease Control and Prevention: KCDCP, 2009). A survey of the snacks sold within the stores of the Green Food Zone in Gwangju showed that 32 items of 61 snacks are HCFLNV and that many sodas are sold (Parent-Teacher Association: PTA, 2009).

Various children's snacks are being sold on the way to schools the children frequent and those that are classified as HCFLNV are especially tempting. Some of the snacks sold within the stores of the Green Food Zone are HCFLNV that are correlated to causing poor physical health among children. The children's snacks sold within the convenience stores of the Green Food Zone are comparatively cheap when compared to a child's spending money.

The MHW made 'A Five-year Plan for Children and Teen Agers' in 2008 and has provided various policies for the effectiveness of the plan and the legislation of relevant acts that concern child food safety. The Special Act on the Safety Management of Children's Dietary Life was legislated based on the above social issues and has resulted in various studies and political considerations for children food safety.

The Special Act on the Safety Management of Children's Dietary Life, 200 meters of school boundaries are designated as Green Food Zone (children's food safety zone) and outstanding business stores for children are selected. The outstanding business stores will not sell foods containing HCFLCV. The Special Act also includes a prohibition of the sale of food that is harmful for emotional development and a prohibition of HCFLCV advertisements during children's prime-time television viewing times. However, the policies have not yet substantially influenced consumer awareness of food safety and application systems of outstanding business for children are not finalized because of the indifference by sellers (Financial news, 2010. 9. 29).

Previous child food safety studies have mainly focused on the nutrition and safety of children's snacks, such as the amount of prohibited artificial color (Korea Consumer Agency: KCA, 2009; Kim et al., 2008), the degree of microbe contamination (Na et al., 2011; Seo et al., 2009), the amount of caffeine (Kim et al., 2009), the amount of sugar (Choi et al., 2008), and the tampering with best before dates (KCA, 2009; Choi, 2004). There have been several papers about the sales and consumption of 'children's snacks' (KFDA, 2005; Chung, 2007). However, the real state of HCFLNV sales (PTA, 2009) have been surveyed in only a few areas and require more research. Therefore, it is preferentially required to survey the sales of HCFLNV that threaten the health and nutrition of young children.

This study surveys the sales of 'children's snacks' sold within the Green Food Zone and that of HCFLNV. The main purposes of this study are the analyses of foods according to the KFDA Program for HCFLNV and the analyses of differences in the real state of HCFLNV dependent on relevant factors, such as food type, school type, country of origin, the scale of manufacturing company, area and price. Based on the analyses, educational and political implications have been sought that will form nutritious dietary habits, contribute to the prevention of obesity, and improve health in child consumers.

\section{LITERATURE REVIEW}

\section{The Significance of HCFLNV}

The Special Act on the Safety Management of Children's Dietary Life (SMCDL), 'children', 'children's snacks' and HCFLNV are properly defined. In the act, 'children's snacks' mean foods that children prefer or often eat as defined by 'the Food Sanitation Act' or 'Livestock Products Sanitation Act'. They should be one of the foods defined by Presidential Decree (Article 2 Clause 2). Children are defined as students or according to the Children's Welfare Law.

'Children's Snacks' include biscuits, candies, 
frozen novelties, Breads and chocolate (confectionery section) and processed milk, yogurt, ice cream and fish paste(dairy product section) and fruit/vegetable juice or drinks, sodas, yogurt drinks, mixed drinks (drink section) and kimbab, hamburgers, sandwiches (instant foods section). In this study, 'children's snacks' sold within the stores of the Green Food Zone are mainly surveyed and processed foods are not included.

HCFLNV are children's snacks that have high calories and low nutrition in terms of KFDA standards that are correlated with childhood obesity and malnutrition (SMCDL Article 2 Clause 2). The KFDA classifies HCFLNV into snacks or meals. The criteria of 'children's snacks' are: 1) Foods the contain over $250 \mathrm{kcal}$ and less than $2 \mathrm{~g}$ of protein per serving. 2) Foods with over $4 \mathrm{~g}$ of saturated fat and less than of $2 \mathrm{~g}$ protein per serving. 3) Foods that contain over $17 \mathrm{~g}$ of sugar and less than $2 \mathrm{~g}$ of protein per serving. 4) Foods that contain over 500 kcal, over $4 \mathrm{~g}$ of saturated fat, and over $34 \mathrm{~g}$ of sugar per serving (among the foods not categorized in 1) and 3). Foods under $30 \mathrm{~g}$ per serving size are calculated as $30 \mathrm{~g}$.

Nutrition labeling marked on the outside of foods based on the above criteria can be used to identify HCFLNV. In this study, only 'children's snacks' sold within the Green Food Zone stores are investigated and analyzed.

\section{Policies Relevant to HCFLNV}

The basic nationwide framework for child food safety has been developed with Comprehensive Measures for Child Food Safety in Korea since 2006. The measures were announced on Feb, 2007 and The Special Act on the Safety Management of Children's Dietary Life was legislated on March, 2009 (enforced since March 2009) that is the basic and fundamental framework for children's dietary life. The Act has been enforced since March 2009 and the Green Food Zone was designated within $200 \mathrm{~m}$ of school boundaries. The public has supported and supervised the improvements of selling conditions for convenience stores that prohibit the sales of HCFLNV and provide the continuous monitoring of low-quality foods by appointing consumer group members as child food guardians (Kim, 2010).

One of the biggest problems of HCFLNV is that too much sugar, fat and sodium are correlated with an increase in child obesity. If any foods are designated as HCFLNV (based on the three ingredients) they are prohibited from being sold within Green Food Zone and from being advertised during children's prime time television viewing (SMCDL Article 8 Clause 10).

In the United States, the Healthy Hunger-free kids Act was legislated on Dec., 2010 and 4.5 billion dollars will have been granted over the next 10 years. The key points of the Act are to support free lunches for low-income children and prohibit vending machine sales of junk food within schools. According to the Act, spaghetti made of whole-wheat flour, pizzas and fresh fruits will be served for lunch at primary schools in the United States instead of hotdogs, fried chicken and processed foods, (mbn, 2010. 12. 14). Since 2005, sodas have been prohibited in all public school vending machines (Yonhap News, 2010. 5. 28).

In the European Union, there is an agreement that no vending machines are installed in primary schools, no drinks be advertised for children under 12 , and that they are monitoring each other (Korea Consumer Council, 2010). The WHICH (a consumer group in England) has been driving a campaign against too much fat, sugar, sodium for children health since 2004, against junk food since 2007 and against marketing to children by food industries (Korea Consumer Council, 2010).

\section{Studies of Consuming 'children's Snacks' and HCFLNV}

Current concerns over dietary lives (as the proportion of eating out and the consumption of fast food increases) have increased the concerns over malnutrition and the rate of young children eating high calorie, high fat, and high sodium food (Kim et al., 2009). There are other reports about disproportional physical conditions and child malnutrition of the (MEST, MHW \& KCDCP, 2009). The rates of child obesity are $13.7 \%$ among males, $7.5 \%$ among females and are in line with similar results from 2007 (MEST, MHW \& KCDCP, 2009). The results of a survey by MEST showed increased rates of obesity 
(in students aged 7-17) from $11.6 \%$ of 2006 to $13.2 \%$ of 2009; in addition, chronic obesity, (1.5 times greater than standard obesity) increased from $0.8 \%$ to $1.1 \%$ (MEST, 2010). The survey results in 2009 showed a frequent intake of soda for middle and high school students (MEST, MHW \& KCDCP, 2009).

The intake of snacks are reported to influence the amount of calories and nutrients (Basdevant et al., 1993, Hamp et al.2003) as well as adolescent obesity (Nicklas et al., 2003). Sodas, candies, and chocolates are strongly correlated to child obesity and dental problems in some studies (Sheiham, 2001; Giammattie et al., 2003; Moynihan \& Petersen, 2004); however, snack intakes are not reported to influence weight increase and body fat percentage in other studies (Phillips et al., 2004; Han \& Joo, 2005). Fruit (usually taken as snacks) are reported to prevent obesity (Berkey et al., 2004), ischemic (Johnsen et al., 2003), and Type 2 diabetes, metabolic syndrome (Choi et al., 2005). Processed foods indicate concerns about unsanitary conditions and food additives; however, sub-nutrition is a comparatively low issue (Jung et al., 2009). A child's choice of foods is influenced by family background, socialcultural environments, and the relationship between children and parents (Birch, 1981; Birch, 1987). In choosing snacks, taste is considered to be the most important factor for children and mothers are most influential over them (Jang, 2005). Increases of nuclear family, household income, various processed food products, birthrate decreases, mass media development and more employment opportunities for mothers are reported to make a child's choice of foods various and bountiful; however, at the same time too concentrated on one side (Jang, 2005).

\section{Children's Snacks Sales}

Children's snacks are mostly sold at convenience stores in the GwyungIn area, and $44.6 \%$ of them sell precooked foods (Koh, 2005). The artificial colors contained in children's snacks sold within the Green Food Zone in the GwyungIn area need to be analyzed with the understanding that more than one artificial color is used (Kim et al., 2008). The survey results of children's snacks sold within the primary
Green Food Zone in Gwangju (conducted from March to Oct. of 2008) showed 2 cases of acid value violation, 3 cases of food poisoning, 2 cases of staphylococcus aureus, and 1 case of colon bacillus among 309 cases. The total of 250 cases are from domestic foods and 50 cases are from imported ones (Seo et al., 2009). A total of $90.6 \%$ of the schools surveyed sold sodas from vending machines according to research on 160 Korean middle and high schools in 2006 (Shin, 2006). Caffeine was found in coffee-flavored milk, coke, chocolate-flavored milk based on the survey result of children's preferred drinks and the amount of caffeine in them. The survey of children's preferred ice cream and drinks showed worries about the increased intake of caffeine (more than recommended) and the use of prohibited or unmarked artificial colors (KCA, 2009). Most foods sold within Green Food Zone are reported to contain too much sugar, $34 \%-100 \%$ (Choi et al., 2008).

Previous research has focused on hygiene, sodas sales, sugar amount, the degree of artificial color use and food poisoning; however, there remains insufficient concern about nationwide Korean HCFLNV sales.

\section{METHODOLOGY \\ Research Questions}

The Research Questions of this study are as follows.

1. What is the state of children snacks sales within the Green Food Zone?

2. What is the state of HCFLNV sales within the Green Food Zone?

3. Are there any differences of HCFLNV sales within the Green Food Zone that depend on relevant variables (food type, country of origin, scale of manufacturing company, and price)?

\section{Sample and Instruments}

Data was gathered through a literature study and the labels of children's snacks were analyzed by direct purchase. In the study, children's snacks sold at 150 stores within the Green Food Zone across Korea 


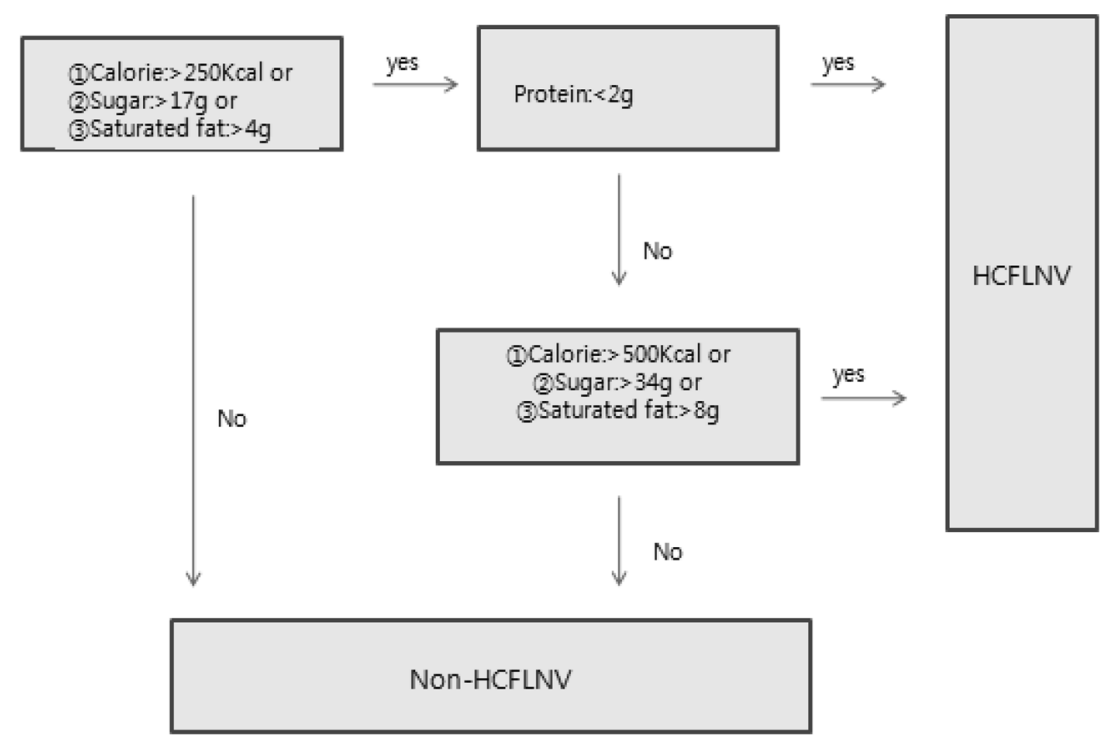

Figure 1. KFDA Program for HCFLNV (for Snacks)

(except Jeju-do province) were collected from May to June, 2010. All kinds of items sold within the Green Food Zone were gathered and classified by lists. Sampling Procedures were done among primary, middle, and high schools across Korea (except Jejudo province) by the stratified sampling method. Such factors such as primary, middle and high schools, coed, boys' and girls' schools, and the number of students are considered in choosing schools. For the second step, one convenience store that sells children's snacks near the school was investigated. Trained monitors (one group of two members) visit and purchase children's snacks to create label lists and categorize nutritional content. The data gathered is analyzed using the KFDA program for HCFLNV based on frequency, percentage, crosstabs and $\mathrm{X}^{2}$.

\section{Measurements of Variables}

Definition of HCFLNV: 'children's snacks' that have higher calorie foods and lower nutritional values than the criteria regulated by the KFDA, cause child obesity (or malnutrition), and consist of snacks and meals. In this study, only snacks are investigated and analyzed. The KFDA Program for HCFLNV according the criteria regulated by the KFDA is given in Figure 1. HCFLNV was identified using the program based on the nutrition ingredients marked on the labels.

Food types, countries of origin, the scale of manufacturing company, prices: Food types were selected to be suitable children's snacks by the criteria of Korean Food Standard Codex. Food types were classified as cookies, candies, ice-cream, breads, chocolates, processed milk, fish products, vegetable drinks, sodas and mixed drinks. Countries of origin were classified as domestic, overseas and unidentified. The scale of manufacturing company was classified as major companies, among 1,000 ones ranked by the KCCI and small businesses. Prices were classified by 100 won level.

\section{DATA ANALYSES AND RESULTS}

\section{Children's Snacks Sales}

A total of 517 foods classified as children's snacks were according to the criteria of SMCDL among a total of 645 foods gathered within 150 Green Food Zones in Korea. Food types, school types, countries of origin, the scale of manufacturing company, region, prices of children's snacks are investigated and summarized in Table 1. A total of 218 candies (42.2\%), 145 cookies (28.0\%), 86 chocolates (16.6\%), and 31 Breads (6.0\%) occupy a large proportion (in 
Table 1. Real State of Children's Snacks Sales

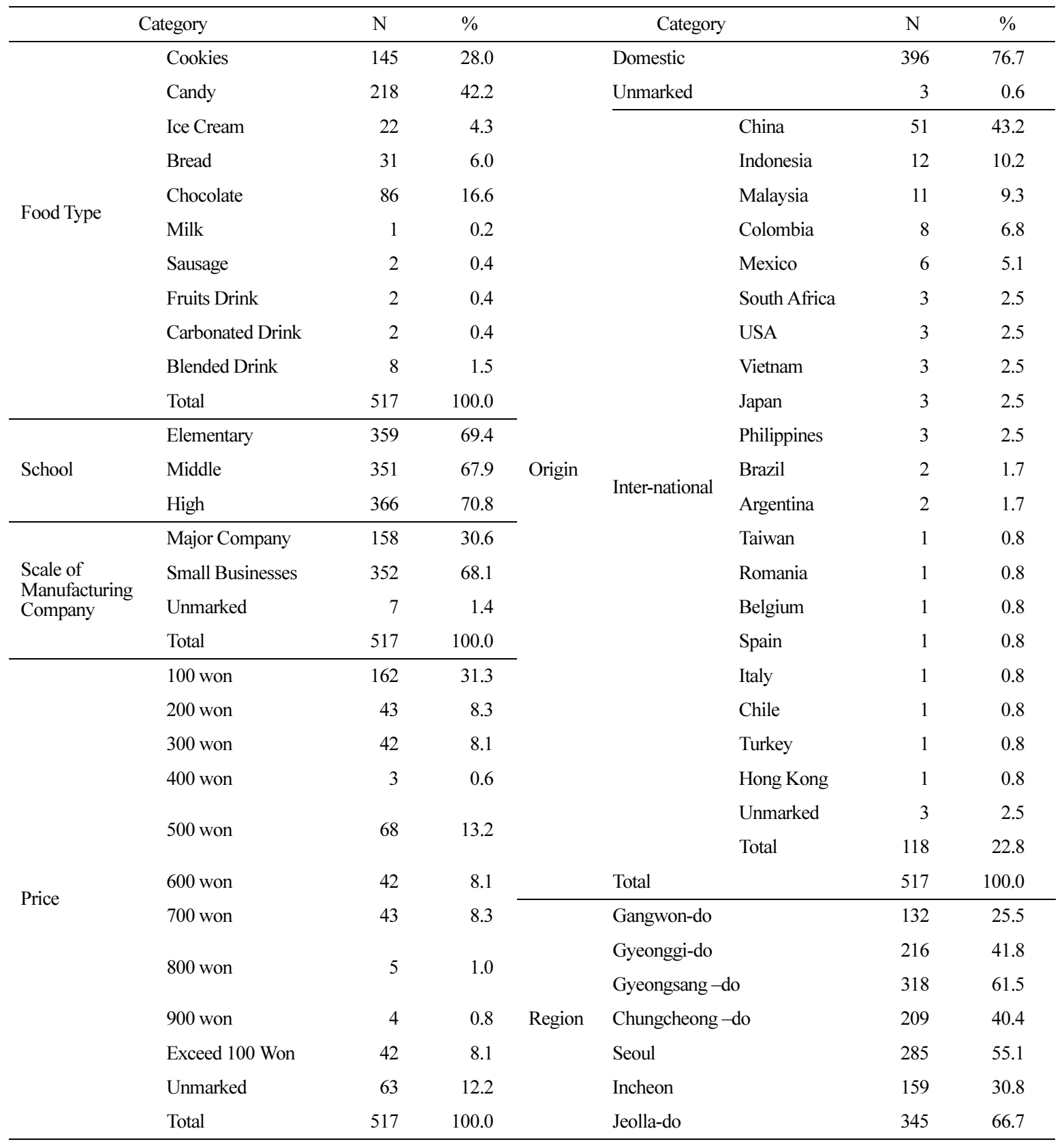

order) and indicate the differences. The total of 359 primary schools (69.4\%), 351 middle schools (67.9\%), 366 high schools $(70.7 \%)$ consist of the parts of school types that indicate that children's snacks are mostly sold around high schools.

The classification of countries of origin showed 396 domestic (76.6\%), 118 overseas (22.8\%) imported from 20 countries and 3 unidentified foods. A total of 51 foods are from China (43.2\%), 12 from Indonesia (10.2\%), and 11 from Malaysia (9.3\%). In regards to the scale of manufacturing company, 352 foods are manufactured by small businesses (68.1\%), 158 by major companies (30.6\%), 7 foods are unmarked (1.4\%). Regions are classified into 7 (except Jeju-do province) and indicate 345 foods (66.7\%, 345 items among the whole 517) in Jeolla- 
do, 318 (61.5\%) in Gyeongsang-do, 285 (55.1) in Seoul and 216 (41.8\%) in Gyeonggi-do. Region and school variables have multiple responses. By the prices, the food around 100 won are the most, 162 $(31.3 \%)$, ones around 500 won, $68(13.2 \%)$, ones around 700 won, $43(8.3 \%)$, ones around 200 won 43 $(8.3 \%)$, ones around 300 won, $42(8.1 \%)$, ones around 600 won, $42(8.1 \%)$, ones over 1000 won, 42 (8.1\%), and unidentified ones, 63 (12.2\%).

In 2010, the study showed a little decrease of cookies, candies and fish products with little increase compared to Breads (Ha et al., 2009). The survey results of Daejeon in 2009 showed the frequencies of sales such as candies, cookies, chocolates, and sodas (Korea Consumer Council, 2010). In regards to the scale of manufacturing company, the number of major companies doubled and that of small businesses decreased (Ha et al., 2009). In regards to prices, the sale of foods around 100 won decreased $10 \%$ compared with those of 2009. These results demand the necessity to improve about half of the children's snacks sold within Green Food Zone (that are lowpriced and less than 300 won) and the 63 unmarked ones.

\section{HCFLNV Children's Snacks}

The results of Question 2 and Question 3 are represented in this section.

The analyses of HCFLNV children's snacks Among 645 foods gathered within 150 Green Food Zone across the country, 517 foods were classified as children's snacks by SASMCD. A total of 509 foods of the 517 ones were analyzed except for 8 that could not be analyzed as due to a lack of nutrition labeling. A total of 186 foods (36.5\%) of the 509 were proved to be HCFLNV (Table 2) after applying the KFDA program for HCFLNV. Compared with the result of Ha et al. (2009), 39.7\% (155 items of the 390 ones) being HCFLNV, the study result show little decrease in HCFLNV. There are substantial differences between in the rate of HCFLNV found in Gwangju, $52.45 \%$ (32 items among the whole 61).

The above results show the high rates of HCFLNV of children's snacks, more than one third of them demand urgent measures for improvement;
Table 2. Real State of HCFLNV sold within Green Food Zone

\begin{tabular}{cc}
\hline Category & $\mathrm{N}$ \\
\hline Total & 509 \\
HCFLNV & 186 \\
$\%$ & 36.5 \\
\hline
\end{tabular}

however, compared to 2009 , the $3 \%$ decrease of the rate shows a small improvement for child food safety within the Green Food Zone.

Analysis result of HCFLNV depending on relevant variables All the HCFLNV foods identified by the KFDA program are analyzed based on the classification of food types, country of origin, scale of manufacturing company, and price. The results are as follow.

(1) Real state of HCFLNV by food types The rates of HCFLNV are different depending on the food types $\left(\mathrm{x}^{2}=136.2, \mathrm{p}<.001\right)$.

Among the 186 foods identified as HCFLNV, candies were the biggest part (137 items), chocolates (25), and then cookies (14 items) (Table 3 ). The rate of candies among HCFLNV (137 items) of the 214 (64\%), is top ranked one.

(2) Real state of HCFLNV by the country of origin

The rates of HCFLNV are different depending on the country of origin $\left(\mathrm{x}^{2}=24.80, \mathrm{p}<.001\right)$. A total of 120 items among 185 HCFLNV are domestic products and 65 items are overseas (Table 4). The rate of overseas products increase considerably when compared with the survey result $(25.8 \%)$ of Ha et al. in 2009; however, $56.0 \%$ of current overseas products are classified as HCFLNV.

(3) Real state of HCFLNV by the scale of manufacturing company

The rates of HCFLNV are different depending on the scale of manufacturing company $\left(x^{2}=18.20\right.$, $\mathrm{p}<.001)$. A total of 147 items among 183 HCFLNV sold within school boundaries are made by small businesses and $42.5 \%$ of products made by small 
Table 3. Real State of HCFLNV by Food Types

\begin{tabular}{|c|c|c|c|c|c|}
\hline \multirow{2}{*}{ Category } & HCFLNV & Non-HCFLNV & Total & \multirow{2}{*}{$\begin{array}{l}\% \text { of Each Food } \\
\text { Type of HCFLNV }\end{array}$} & \multirow{2}{*}{$x^{2}$} \\
\hline & $\mathrm{N}(\%)$ & $\mathrm{N}(\%)$ & $\mathrm{N}(\%)$ & & \\
\hline Cookie & $14(7.5)$ & $130(40.2)$ & $144(28.3)$ & 9.7 & \multirow{7}{*}{$\begin{array}{l}136.25^{* * *} \\
\mathrm{df}=5\end{array}$} \\
\hline Candy & $137(73.7)$ & $77(23.8)$ & $214(42.0)$ & 64.0 & \\
\hline Ice Cream & $3(1.6)$ & $18(5.6)$ & $21(4.1)$ & 14.3 & \\
\hline Bread & $1(0.5)$ & $30(9.3)$ & $31(6.1)$ & 3.2 & \\
\hline Chocolate & 25 (13.4) & $61(18.9)$ & $86(16.9)$ & 29.1 & \\
\hline Other & $6(3.2)$ & $7(2.2)$ & $13(2.6)$ & 46.2 & \\
\hline Total & $186(36.5)$ & $323(63.5)$ & $509(100.0)$ & 36.5 & \\
\hline
\end{tabular}

$* * * \mathrm{p}<.001$

Table 4. Real state of HCFLNV by Country of Origin

\begin{tabular}{lrcccc}
\hline \multirow{2}{*}{ Category } & HCFLNV & Non-HCFLNV & Total & $\begin{array}{c}\text { \% of Each Producer } \\
\text { of HCFLNV }\end{array}$ & $\mathrm{x}^{2}$ \\
\cline { 2 - 4 } & $\mathrm{N}(\%)$ & $\mathrm{N}(\%)$ & $\mathrm{N}(\%)$ & 30.7 & \\
\hline Domestic & $120(64.9)$ & $271(84.2)$ & $391(77.1)$ & & \\
International & $6(35.1)$ & $51(15.8)$ & $116(22.9)$ & 56.0 & $24.80^{* * *} \mathrm{df}=1$ \\
Total & $185(36.5)$ & $322(63.5)$ & $507(100.0)$ & 36.5 & \\
\hline
\end{tabular}

$* * * \mathrm{p}<.001$

Table 5. Real state of HCFLNV by the Scale of Manufacturing Company

\begin{tabular}{lccccc}
\hline \multirow{2}{*}{ Category } & HCFLNV & Non-HCFLNV & Total & $\begin{array}{c}\text { \% of Each Company } \\
\text { Scale of HCFLNV }\end{array}$ & $x^{2}$ \\
\cline { 2 - 4 } & $\mathrm{N}(\%)$ & $\mathrm{N}(\%)$ & $\mathrm{N}(\%)$ & 22.8 & $18.20^{* * *}$ \\
Major Company & $36(19.7)$ & $122(38.0)$ & $158(31.3)$ & 42.5 & $\mathrm{df}=1$ \\
Small Businesses & $147(80.3)$ & $199(62.0)$ & $346(68.7)$ & 36.3 & \\
Total & $183(36.3)$ & $321(63.7)$ & $504(100.0)$ & & \\
\hline
\end{tabular}

$* * * \mathrm{p}<.001$

Table 6. Real State of HCFLNV by Price

\begin{tabular}{|c|c|c|c|c|c|}
\hline \multirow{2}{*}{ Category } & "HCFLNV & Non-HCFLNV & Total & \multirow{2}{*}{$\begin{array}{l}\% \text { of Each Price of } \\
\text { HCFLNV }\end{array}$} & \multirow{2}{*}{$x^{2}$} \\
\hline & $\mathrm{N}(\%)$ & $\mathrm{N}(\%)$ & $\mathrm{N}(\%)$ & & \\
\hline 0-100 Won & $90(55.9)$ & $69(24.0)$ & $159(35.5)$ & 56.6 & \multirow{4}{*}{$\begin{array}{l}55.02 * * * \\
\mathrm{df}=2\end{array}$} \\
\hline 101-500 Won & $50(31.3)$ & $103(35.9)$ & $153(34.2)$ & 32.7 & \\
\hline Exceed 500 Won & $21(13.0)$ & $115(40.1)$ & $136(30.4)$ & 15.4 & \\
\hline Total & $161(35.9)$ & $287(64.1)$ & $448(100.0)$ & 35.9 & \\
\hline
\end{tabular}

$* * * \mathrm{p}<.001$

businesses are HCFLNV that show a higher rate compared to major companies (Table 5). In the survey of Ha et al. 2009, the rate of products made by major companies was higher, but in this study, the result was reversed.

(4) Real state of HCFLNV by price

The rates of HCFLNV are different depending on 
the price $\left(\mathrm{x}^{2}=55.02, \mathrm{p}<.001\right)$. There are 90 items (56.6\%) priced 100 won or less among $161 \mathrm{HCFLNV}$ items except for the price of unmarked products (Table 6). Since $31.3 \%$ of the whole products are HCFLNV, the rate of cheap food less than 100 won is high. Candies have the highest rate of HCFLNV among food types, overseas products have a higher rate of HCFLNV than domestic ones and small company products have a higher rate of HCFLNV than major ones that shows the necessity for improvements.

\section{CONCLUSIONS AND IMPLICATIONS}

In this section, the analyses of children's snacks sales within the Green Food Zone, the state of HCFLNV, and the differences depending on relevant factors will be summarized and educational and political implications will be provided.

First, the general state of children's snacks sales can be summarized as follow. The number of children's snacks is 517 items among the total of 645 gathered within 150 Green Food Zone. Candies represent the most, next cookies, chocolates, and then breads; most items are sold around high schools (among primary, middle and high schools). The rate of domestic products is the highest (76.6\%), and overseas products are from 20 countries; the main country is China, next Indonesia, and last Malaysia. The province that shows the most number of children's snacks items is Jeolla-do (66.7\%), and the province that shows the fewest number of children's snacks items is Gwangwon-do (25.5\%). The rate of small businesses products are higher than major companies and the rate of price less than 100 won is the highest (31.3\%).

The current study showed some similar results compared to another survey by Ha et al. (2009); the sequence of sales number are candies, cookies and chocolates. In 2009, the number of products made by small businesses is more than the increase of major companies in this study. Concerning prices, the rate of 100 won or less is the highest in this study as well as in the survey of 2009. Low-price foods have a health hazard for children or security and significant efforts for systems or policies are needed.

First, considering there have already been overseas products from 20 countries, there will be some limits in our efforts for children's food safety that require cooperation with other countries around the world. Second, improvements for the price-marked system are needed. The system was recommended to convenience stores; however, 63 cases with prices unmarked were found out. At the time of this current survey, an open price system was conducted but there were many convenience stores with unmarked prices. Third, food manufacturers need to make labels easier to read. In this study there were few violations and just 7 cases of unmarked company names on the label; in addition, some product labels had too small of letters and an inappropriate color match on the label that made it hard to read.

Second, in the real state survey there were 186 HCFLNV (36.0\%) among children's snacks sold within the Green Food Zone. Compared with the results of the study (Ha et al., 2009), 186 cases $(36.0 \%)$, there has been a little improvement over 2009; however, the rate of improvement would have been higher in consideration of 75 cases excluded in the analysis due to the absence of nutritional labels. In 2009 there were 196 HCFLNV (36.0\%) products (28.0\%) among 701 sold at school stores, the increase of HCFLNV (36.0\%) requires political concern about stores within the Green Food Zone. More practical policies for not selling HCFLNV are needed due to the limitation of HCFLNV sales that are possible due to SASMCD.

Consumer education program development and implementations for parents are urgently needed because child obesity (due to excessive sugar or fat intake) could lead to adult diabetes. (1) System improvements are needed for the easy recognition of HCFLNV consumers. The best way for child consumers is the marking HCFLNV on the outside of the products that requires a system improvement for such regulation. (2) There are some cases where the only amount per serving size was marked to avoid classification as HCFLNV. In order to avoid being classified as HCFLNV, manufacturing company reduced the size instead of the amount of calories, fat 
and sugar. More efforts are needed to make more healthy foods. The policies need to be considered that we extend the limitation of HCFLNV sales beyond current Green Food Zone, from outstanding stores and in-school stores to all stores within the Green Food Zone. (3) There is still short-term, limited inspection just on the labeling by KFDA or local governments, but continuous monitoring on HCFLNV is needed that will create a safer child food environment. In addition, consumer education for children in choosing foods needs to be programmed and experienced (not to choose just by shapes or colors) but by interest in nutrients, such as calories, sugar and fat.

Especially even among vegetable beverages (usually thought to be healthy) there are HCFLNV products that make it absolutely necessary to obtain consumer education that will help consumers check nutrition labeling instead of choosing by desire when purchasing foods.

This study focused on children's snacks that are sold in the convenience stores. Future studies where the research includes more diverse children's snacks and relevant variables are needed. We expect the study for a strategy and consumer policy to reduce HCFLNV for children's food safety.

\section{REFERENCES}

Basdevant, A., Craplet, C., \& Guy-grand, B. (1993). Snacking patterns in obese French women, Appetite 21(1), 17-23.

Berkey, C. S., Rockett, H. R. H., E., Field, A. E., Gillman, M. W., \& Colditz, G. A. (2004). Sugar-added beverages and adolescent weight change, Obesity Research 12, 778-788.

Birch, L. L., Marlin D. W., Kramer L., \& Peyer C. (1981). Mother-child interaction patterns and the degree of fatness in children, Journal of Nutrition Education 13(1), 17-21.

Birch, L. L. (1987). The role of experience in children's food acceptance patterns, Journal of America Diet Association 87(9), 536-540.

Choi, H. K., Willett, W. C., Stampfer, M. J., Rimm. E.,
\& Hu, F. B. (2005). Dairy consumption and risk of type 2 diabetes mellitus in men: a prospective study, Arch Intern Med 165, 997-1003.

Choi, M. H., Kwon, K. I., Kim, J. Y., Lee, J. S., Kim, J. W., Park, H. K., Kim, M. C., \& Kim, G. H. (2008). Monitoring of total sugar contents in processed foods and noncommercial foodservice foods, Korean Journal of Food Science Technology, 40(3), 337-342.

Choi, U. K. (2004). Research on Actual Condition of Distribution and Analysis on Hazard Point of Children's Favorite Foods Distributed around Elementary Schools in Daegu/Gyoungbuk Area, KFDA.

Chung, K. H. (2007). A study of on evaluation system for child food safety, KFDA.

Financial News 2010. 9. 29 'Green Food Zone designated by the KFDA have no effect on: from http:// www.fnnews.com

Giammattei, J., Blix, G., Marshak, H. H., Wollitzer, A. O., \& Pettitt, D. J. (2003). Television watching and soft drink consumption: associations with obesity in 11 to 13-year-old schoolchildren, Arch Pediatr Adolesc Med 157, 882-886.

Hampl, J. S., Heaton, C. L. \& Taylor, C. A. (2003). Snacking patterns influence energy and nutrient intakes but not body mass index, Journal of Human Nutrition Diet 16(1), 3-11.

Han, Y. S., \& Joo, N. M. (2005). An analysis on the factors of adolescence obesity, Korean Journal of Food Culture, 20(2), 172-185.

Ha, S. D., et al. (2009). Monitoring the Market Environment of children's Snack around School areas, KFDA.

Jang, S. H. (2005). Studies on Snack food consumption of Elementary School Students and Motherly Awareness for Its Actual Condition, Master's Thesis, Chonnam National University.

Johnsen, S. P., Overvad, K., Stripp, C., Tjonneland, A., Husted, S. E., \& Sorensen, H. T. (2003). Intake of fruit and vegetables and the risk of ischemic stroke in a cohort of Danish men and women, America Journal of Clinic Nutrition 78(1), 57-64.

Jung, J. H., Song, K. H., \& Yoon, J. Y. (2009). A study on the parents' perceptions of children's favorite 
foods, Korean journal of Community nutrition 14(1), 67-76.

Kalsbeek, H., \& Verrips, G. H. (1994). Consumption of sweet snacks and caries experience of primary school children, Caries Res 28(6), 477-483.

Kim, E. K. (2001). Eating behavior and nutrition related problems in Korean Children, Korean Journal of Community Nutrition, 6(5), 905-920.

Kim, H. R., Seo, S. H., Kim, E. G. N., \& Lee, J. W. (2009), A Study on the Development of Policy and Strategies for National Overweight and Obesity Prevention Programs in Children and Adolescents, Korea Institute for Health and Social Affairs.

Kim, H. R. (2010). An overview of food safety and nutrition policy for children and tasks ahead, Health \& Welfare forum, vol. 161, 27-36.

Kim, H. Y., Nam, H. S., Jung, Y. H., Lee, J. H., \& Ha, S. C. (2008). Artificial colors in foods distributed throughout the Gyeong-In region - monitoring favorite food Items of children near elementary schools -, Korean Journal Food Science Technology, 40(3), 243-250.

Kim, S. D., Yun, E. S., Chang, M. S., Park, Y. A., Jung, S. O., Kim, D. G., Kim, Y. C., Chae, Y. Z., \& Kim, M. Y. (2009). Survey of daily caffeine intake form children's beverage Consumption and the Effectiveness of Nutrition Education, Journal of Korean Society food Science and Nutrition, 38(6), 709-720.

Klesges R. C., Stein R. J., Eck L. H., Isbell T. R., \& Klesges L. M. (1991). Parental influence on food selection in young children and its relationships to childhood obesity, American Journal of Clinical Nutrition, 54(6), 859-864.

Koh, K. R. (2005). Survey and management of hazardous materials in favorite children's food, KFDA.

Korea Consumer Agency (2009). Children's favorite food of food additives (artificial coloring), Safety Survey Report.

Korea Consumer Council (2010). Green Food Zone survey, Monthly Consumer 12.

Korea Food and Drug Administration (2005). Survey and management of hazardous materials in favorite children's food
Korea Food and Drug Administration (2009). Children's food safety management guidelines.

Korea Statistics Office (2010). Korea Social Research: from http://www.kostar.go.kr

Lee, Y. S., Lim, H. S., An, H. S., \& Jang, N. S. (2003). Nutrition of life cycle, Gyomunsa.

MBN (2010). United States, school feeding improves quality (2010. 12. 14), from: http://www.mk.co.kr

Ministry of Education, Science and Technology (2010). 2009 School health examination survey.

Health and Nutrition survey.

Ministry of Education, Science and Technology, Ministry of Health and Welfare \& Korea Centers of Disease Control and Prevention (2009). $5^{\text {th }}$ Adolescent Health Behavior Survey Online, from http:// yhs.cdc.go.kr.

Moynihan, P., \& Petersen, P. E. (2004). Diet, nutrition and the prevention of dental diseases, Public Health Nutrition 7(1A), 201-226.

Na, B. J, Choi, S. Y., Kim, S. C., Lee, D. H., Seo, I. W., \& Ha, S. D. (2011). Microbiological hazard analysis in children snacks around schools, 26(2), 182-185.

Na, H. S. (2010). A Survey on the Sales and Consumption of Children's Favorite Foods in the Green Food Zone of Jeoniu, Master's Thesis, Wonkwang University.

Nicklas T. A, Yang S. J, Baranowski T., Zakeri I., \& Berenson G. (2003). Eating patterns and obesity in children, the bogalusa heart study, American Journal of Prevent Medicine 25(1), 9-16.

Park, N. R. \& Sohn, S. H. (2010). The effects of food safety education on children's food safety knowledge, belief, attitude and behavior, Consumer Policy and Education Review, 6(1), 47-66.

Parent-Teacher Association Gangju Branch (2009). Green Food Zone food safety monitoring reportGangju region.

Phillips, S. M., Bandini, L. G., Naumova, E. N., Cyr, H., Colclough, S., Dietz, W. H., \& Aviva Must, A. (2004), Energy-dense snack food intake in adolescence, longitudinal relationship to weight and fatness, Obesity Research 12, 461-472.

Seo, K. W., Kim, J. P., Cho, B. S., Gang, G. L., Yang, Y. 
S., Park, J. T., \& Kim, E. S. (2009). Study on safety of children snacks in school zone, Journal of Food Hygiene Safety 24(2), 154-161.

Shin, H. Y. (2006). Youth policy direction and policy proposals to improve, 2006 National audit policy Kit-12.

Sheilham A. (2001). Dietary effects on dental diseases. Public Health Nutrition 4(2B), 569-591.
Yonhap News (2010). California, Expected to ban sports drinks in the school (2010.5.28): from: http:// www.yonhapnews.co.kr

Received September 30, 2011

Revised December 11,2011

Accepted December 16, 2011 